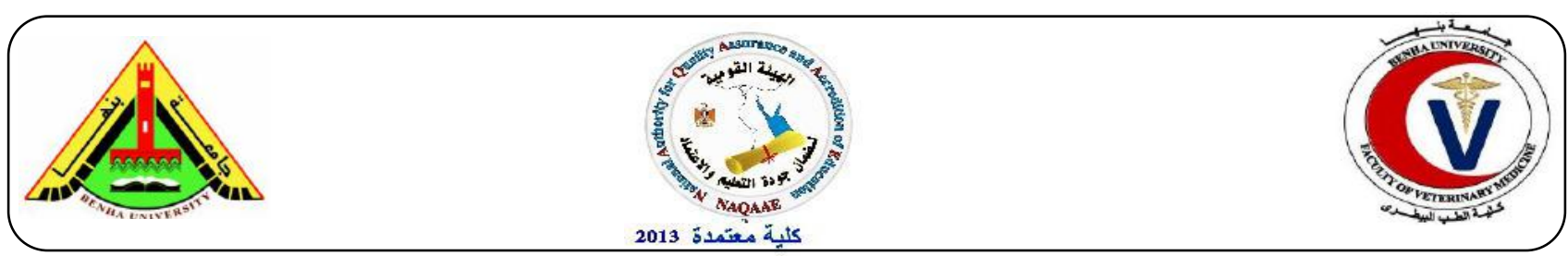

\title{
Biochemical effect of leuprolide, cabergoline and some herbals on ameliorating polycystic ovaries syndrome
}

\author{
Omayma, A.R AbouZaid ${ }^{1}$, Samy, A.H. ${ }^{1}$, Samir, A.A ${ }^{2}$, Fatma, Z.M. ${ }^{1}$ \\ ${ }^{I}$ Department of Biochemistry, Faculty of Veterinary Medicine, Benha University \\ ${ }^{2}$ Department of Animal Hygiene, Faculty of Veterinary Medicine, Benha University
}

\section{A B S T R A C T}

Polycystic ovary syndrome (PCOS) is a set of symptoms due to elevated androgenslin females. Its Signs include irregular or no menstrual periods, heavy periods, excess body and facial hair, acne, pelvic pain, difficulty getting pregnant, and patches of thick, darker, velvety skin. It could be a result from the combination of genetic and environmental factors. Many drugs used for treating this disease. Several hormones have been measured to evaluate PCOS (progesterone, Estradiol, Follicular Stimulating Hormone (FSH), Luteinizing hormone (LH), Total Testosterone, AntiMullerian Hormone (AMH), Thyroid Stimulating Hormone (TSH), Prolactin and histopathological studies. Groups were classified as follow: Group (1) Control, Group (2) Dehydroepiandrosterone (DHEA only), Group (3) (DHEA and flaxseed), Group (4) (DHEA and alfalfa), Group (5) (DHEA and Soya), Group (6) (DHEA and Cabergoline), and Group (7) (DHEA and Leuproline). Results: DHEA in a dose of $(1 \mathrm{mg} / \mathrm{kg})$ induced PCOS and it was clear by significant elevation of (LH/ FSH ratio, total testosterone, $\mathrm{AMH}, \mathrm{TSH}$, Prolactin) and a significant decrease in progesterone and estradiol. Leuproline was the best choice to decrease the symptoms of PCOS followed by cabergoline and the least but still effective were the herbals (Soya, flaxseed, and alfalfa). In conclusion, DHEA could be used for PCOS induction, Leuproline, cabergoline and phytoestrogen containing herbals could be used for treating PCOS symptoms.

Keywords: PCOS, DHEA, Leuproline, Cabergoline, Soya, Alfalfa, Flaxseed.

\section{INTRODUCTION}

Polycystic ovary syndrome (PCOS) is a heterogeneous disorder that is defined by a combination of signs and symptoms of androgen excess (hirsutism and/or hyperandrogenaemia) and ovarian dysfunction (oligo-ovulation and/or polycystic ovarian morphology (PCOM)), provided that other specific diagnoses, such as hyperprolactinaemia and non-classic congenital adrenal hyperplasia, have been excluded (Azziz, et al., 2009).

Clinical signs of PCOS include elevated luteinizing hormone (LH) and gonadotropinreleasing hormone $(\mathrm{GnRH})$ levels, whereas follicular-stimulating hormone (FSH) levels are muted or unchanged. As a result of the increase in $\mathrm{GnRH}$, stimulation of the ovarian thecal cells, in turn, produces more androgens 
(Urbanek, 2007). Typical ways to treat hyperandrogenism include cosmetic, estroprogestins, antiandrogens alone or combined with ethinylestradiol, and if necessary, insulin sensitizers, particularly metformin. Estrogenprogestin compounds may lead to an acceptable improvement of the hyperandrogenic state, and in addition, they are safe and have a positive cost-effectiveness aspect. Their efficacy is mainly justified by the ability of progestin to suppress luteinizing hormone (LH) levels and thus ovarian androgen production, and by the ability of estrogen (specifically ethinylestradiol) to increase sex-hormone-binding globulin, thereby reducing bioavailable free androgens (Renato, 2018).

Leuprolide acetate represents a gonadotropinreleasing hormone agonist that acts as a potent inhibitor of gonadotropin secretion, used as part of the treatment of prostate cancer. Continuous administration results in the suppression of ovarian and testicular steroidogenesis due to decreased levels of LH and FSH with a subsequent decrease in testosterone (male) and oestrogen (female) levels. Leuprolide may also have a direct effect on the testes by a different mechanism not directly related to reduction in serum testosterone (Marta et al., 2014). Antiandrogens block testosterone action in target tissues by interfering with testosterone or dihydrotesterone (DHT) binding to the steroid-binding domain of the androgen receptor.

Steroidal anti-androgens, such as cyproterone acetate, also have some ability to block luteinizing hormone ( $\mathrm{LH})$ secretion, and are therefore associated with many of the sexual effects seen with LHRH agonists. Cabergoline is a dopamine receptor agonist which has higher affinity than dopamine D2 receptors could be helpful in the treatment of hyperprolactinemia patients. It is long-acting dopamine agonists with inhibiting of prolactin in patients with PCOS (Azam et al., 2015).

DHA-S are the most abundant endogeneous circulating steroid hormones. Metabolism of DHA to active androgens, including testosterone and 5-dihydrotestosterone (DHT), occurs in the gonads, liver, adrenals, and peripheral tissues (Russell et al., 2016). Alfalfa (Medicago sativa L.) contains several phytoestrogens that may have healthpromoting effects in humans. (apigenin, coumestrol and luteolin) among the phytoestrogen of alfalfa (Philippe and Wenju, 2006). Daidzein and genistein are the two best characterized isoflavones of soya exerts a phytoestrogenic action could fight hirsutism and hyperandrogenism (Heather and Wendy, 2010). Flaxseed, one of the main constituents are Lignans which act as both antioxidants and phytoestrogens, they have estrogen activity in animals and humans. Flax contains up to 800 times more lignans than other plant foods (Ankit et al., 2014).

\section{Materials and methods}

\subsection{Experimental design:}

This study was performed on 70 female albino rats. Their weights ranged at the beginning of the experiment from $35-50 \mathrm{gm}$, and their age was about 21 days classified randomly into seven groups as follows: Group (1) control group (10 rats) not receives any drugs. Group (2) (10 rats): PCOS was induced by administration of Dehydroepiandrosterone (DHEA) dissolved in sesame oil, administered at a dose of $6 \mathrm{mg} / 100 \mathrm{~g}$ body weight, daily by $\mathrm{S} / \mathrm{c}$ route, for 30 days according to (Elizabeth et al., 2011). Group (3) (10 rats): flaxseed extract was given orally daily at a dose of $500 \mathrm{mg} / \mathrm{kg}$ after PCOS induction by DHA and the flaxseed dose lasted for 35 days according to (Palla et al., 2015). Group (4) (10 rats): alfalfa extract was given orally daily at a dose of $500 \mathrm{mg} / \mathrm{kg}$ after 
PCOS induction by DHA, and alfalfa doses lasted for 35 days according to (Esmaiel et al., 2015). Group (5) (10 rats): Soya beans extract was given orally daily at a dose of $200 \mathrm{mg} / \mathrm{kg}$ after PCOS induction by DHA, and Soya dose lasted for 35 days according to (Belkiz et al., 2014). Group (6) (10 rats): given cabergoline orally at a dose of $0.6 \mathrm{mg} / \mathrm{kg}$ for 35 days, after PCOS induction by DHA, in a according to (Fernando et al., 2013). Group (7) (10 rats): given Leuprorelin (Leuprolide) by $\mathrm{S} / \mathrm{c}$ at a dose $0.07 \mathrm{mg} / \mathrm{kg}$ twice weekly for 35 days after PCOS induction by DHA, according to (Crawford et al., 2015).

\subsection{Materials:}

Leuprolide acetate (Sigma Aldrich, Germany), PEG 200 (Shanghai Runwu Chemical Technology, China), methyl paraben (Arshine Pharmaceutical Co.,China), Cabergoline (Xi'an Norida Bio-Technology Co., Ltd.), DHEA (Shaanxi Pioneer Biotech Co., Ltd.), Herbals were brought from (Agricultural Research Center, Egypt)

\subsection{Drug and additives:}

Leuprolide (prepared as $5 \mathrm{mg}$ of leuprolide dissolved in PEG $2001 \%$ and tween 80 0.1\%, then incorporated into PBS buffer using $0.01 \%$ methyl paraben as a preservative. Cabergoline was prepared as $0.5 \mathrm{mg}$ dissolved in PEG $2001 \%$ and tween $80(0.1 \%)$, then incorporated into PBS buffer using $0.005 \%$ sodium benzoate as a preservative. DHEA prepared by dissolving in sesame oil then using tween $800.1 \%$ as emulsifier and PBS Buffer as a vehicle. Herbals was extracted as ethanolic extract 100 gram herb/liter ethanol, macerated, sonicated for 3 hours, filtered then ethanol evaporated in rotary evaporator, crude extract then dissolved in PBS buffer by homogenization and stirring for 12 hours using $0.005 \%$ sodium benzoate as a preservative.

\section{RESULTS}

\subsection{Biochemical findings:}

The biochemical results showed a significant decrease of (progesterone, Estradiol) concentrations in all groups compared to control group, insignificant decrease in $\mathrm{FSH}$, and a significant increase in (LH, Total testosterone, AMH, TSH, Prolactin) compared to control group. Also, the results showed a significant decrease in (LH, AMH, $\mathrm{TSH}$, Prolactin) and a significant increase of estradiol concentrations in all groups compare to group (2) (DHEA only treated group). Leuproline treated group (group 7) revealed the best results as it was significant from all other treated groups. It has significantly increased in (progesterone, Estradiol) and significantly decreased in (LH, Total testosterone, AMH, TSH, Prolactin) concentrations followed by cabergoline treated group (group 4) that was significantly increased in (estradiol) and significantly decreased in (testosterone) concentrations compared to the herbals treated groups. The results from herbals treated groups revealed a comparable effect of these herbals on the PCOS model.

\subsection{Histopathological results:}

Control group: The surface of ovary consisted of continues sheet covered by a single epithelial layer, usually of cuboidal or low columnar cells. The ovary contain normal follicles at different growth stages including primordial follicles located near the cortical surface and secondary oocytes, tertiary follicles with or without antrum, as well as Graafian follicles, copora lutea which occupy large spaces of the ovary besides atretic follicles.

Histopathological examination of ovary in group (2) showed thick capsule and congested, dilated blood vessels with healthy primordial follicles. Some corpora lutea 
display regression, this is beside to degenerative changes in granulosa lutein cells with hyalinization of their matrix. Hyaline body in granulosa lutein cells could be detected with cystic graffian follicle.

Ovarian tissues in group (3) revealed some pathological, in form of some atretic follicles with congested, dilated blood vessels and fibrous stroma. Ovaries of animals of group (4) occupied with atretic follicles of different stages with fibrous stroma. Healthy Graffian follicles with intact granulosa lutein cells could be detected.
Group (5): Give the same histological profile as group (3) with intact granulosa lutein cells, normal graffian follicle and dilated antrum.

The most prominent lesion in the ovaries of group (6) was atresia, where wide areas of the ovaries occupied by atretic follicles, with dilated lymph. This is beside to degenerative changes in nucleus of cell of atretic follicles.

Moderate pathological alteration in group (7) in the form of Mild cystic follicles and fatty degenerative changes in granulosa lutein cells could be seen also the incidence of atretic follicles was increased.

Table 1: Comparison between control group and different studied groups for all hormones measured.

\begin{tabular}{|c|c|c|c|c|c|c|c|}
\hline Parameters & $\begin{array}{l}\text { Control } \\
\text { Normal }\end{array}$ & $\begin{array}{l}\text { DHEA } \\
\text { induced } \\
\text { PCOS }\end{array}$ & $\begin{array}{c}\text { DHEA } \\
+ \\
\text { Flaxseed }\end{array}$ & $\begin{array}{l}\text { DHEA } \\
+ \\
\text { Alfalfa }\end{array}$ & $\begin{array}{c}\text { DHEA + } \\
\text { Soya } \\
\text { bean }\end{array}$ & $\begin{array}{c}\text { DHEA + } \\
\text { Cabergoline }\end{array}$ & $\begin{array}{c}\text { DHEA + } \\
\text { Leoprolide } \\
\text { (Leuprorelin) }\end{array}$ \\
\hline \multirow[t]{2}{*}{ Progesterone } & 21.95 & 3.26 & 5.95 & 7.26 & 6.82 & 8.58 & 12.61 \\
\hline & $\pm 1.67^{\mathrm{a}}$ & $\pm 0.51^{\mathrm{f}}$ & $\pm 0.63^{\mathrm{e}}$ & $\pm 0.56^{\mathrm{d}}$ & $\pm 0.38^{\mathrm{d}}$ & $\pm 0.61^{\mathrm{c}}$ & $\pm 1.41^{\mathrm{b}}$ \\
\hline \multirow{2}{*}{ Estradiol } & 22.81 & 3.16 & 5.49 & 5.20 & 5.84 & 7.63 & 12.75 \\
\hline & $\pm 2.75^{\mathrm{a}}$ & $\pm 0.30^{\mathrm{e}}$ & $\pm 0.71^{\mathrm{d}}$ & $\pm 0.69^{d}$ & $\pm 0.63^{\mathrm{d}}$ & $\pm 0.57^{\mathrm{c}}$ & $\pm 1.81^{\mathrm{b}}$ \\
\hline \multirow{2}{*}{ FSH } & 5.63 & 2.11 & 3.26 & 2.85 & 2.97 & 3.65 & 3.73 \\
\hline & $\pm 0.28^{\mathrm{a}}$ & $\pm 0.12^{\mathrm{d}}$ & $\pm 0.14^{\mathrm{b}}$ & $\pm 0.13^{\mathrm{c}}$ & $\pm 0.15^{\mathrm{c}}$ & $\pm 0.18^{\mathrm{b}}$ & $\pm 0.17^{\mathrm{b}}$ \\
\hline \multirow{2}{*}{ LH } & 2.82 & 11.25 & 7.08 & 8.72 & 8.44 & 8.40 & 5.53 \\
\hline & $\pm 0.12^{\mathrm{e}}$ & $\pm 0.41^{\mathrm{a}}$ & $\pm 0.35^{\mathrm{c}}$ & $\pm 0.32^{\mathrm{b}}$ & $\pm 0.41^{\mathrm{b}}$ & $\pm 0.36^{\mathrm{b}}$ & $\pm 0.31^{\mathrm{d}}$ \\
\hline \multirow{2}{*}{$\begin{array}{c}\text { Total } \\
\text { testosterone }\end{array}$} & 4.80 & 45.71 & 34.25 & 32.36 & 29.82 & 22.71 & 15.55 \\
\hline & $\pm 0.32^{\mathrm{f}}$ & $\pm 1.79^{\mathrm{a}}$ & $\pm 0.94^{\mathrm{b}}$ & $\pm 0.91^{\mathrm{b}}$ & $\pm 0.87^{\mathrm{c}}$ & $\pm 0.71^{\mathrm{d}}$ & $\pm 0.94^{\mathrm{e}}$ \\
\hline \multirow{2}{*}{$\mathrm{AMH}$} & 3.71 & 19.88 & 14.05 & 14.19 & 13.78 & 11.62 & 8.48 \\
\hline & $\pm 0.22^{\mathrm{e}}$ & $\pm 0.91^{\mathrm{a}}$ & $\pm 0.74^{\mathrm{b}}$ & $\pm 0.58^{\mathrm{b}}$ & $\pm 0.51^{\mathrm{b}}$ & $\pm 0.86^{\mathrm{c}}$ & $\pm 0.15^{\mathrm{d}}$ \\
\hline \multirow{2}{*}{ TSH } & 1.18 & 16.19 & 8.91 & 10.09 & 12.72 & 10.83 & 8.27 \\
\hline & $\pm 0.16^{\mathrm{e}}$ & $\pm 0.56^{\mathrm{a}}$ & $\pm 0.63^{\mathrm{d}}$ & $\pm 0.87^{\mathrm{c}}$ & $\pm 0.48^{\mathrm{b}}$ & $\pm 0.41^{\mathrm{c}}$ & $\pm 0.24^{\mathrm{d}}$ \\
\hline \multirow{2}{*}{ Prolactin } & 3.52 & 11.03 & 9.27 & 8.93 & 8.21 & 7.96 & 5.82 \\
\hline & $\pm 0.17^{\mathrm{e}}$ & $\pm 0.58^{\mathrm{a}}$ & $\pm 0.49^{\mathrm{b}}$ & $\pm 0.50^{\mathrm{b}}$ & $\pm 0.31^{\mathrm{c}}$ & $\pm 0.22^{\mathrm{c}}$ & $\pm 0.25^{\mathrm{d}}$ \\
\hline
\end{tabular}




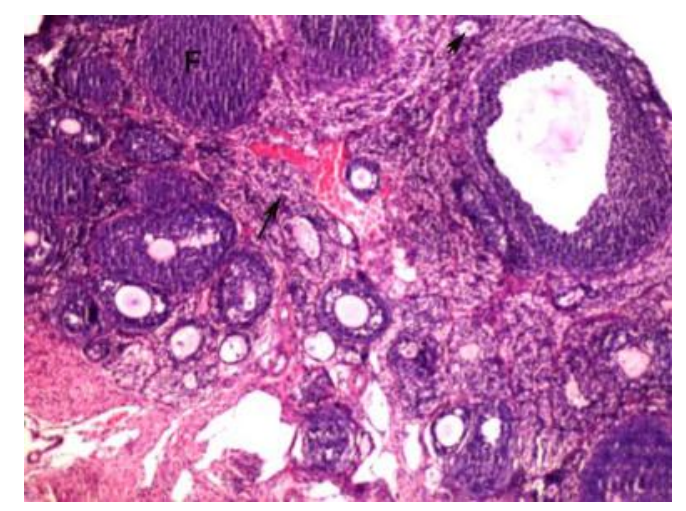

Fig.1. Photomicrograph of ovarian tissues of control group showed primordial follicle (arrow head), follicle (F) and stroma (arrow). (H\& E). (X200).

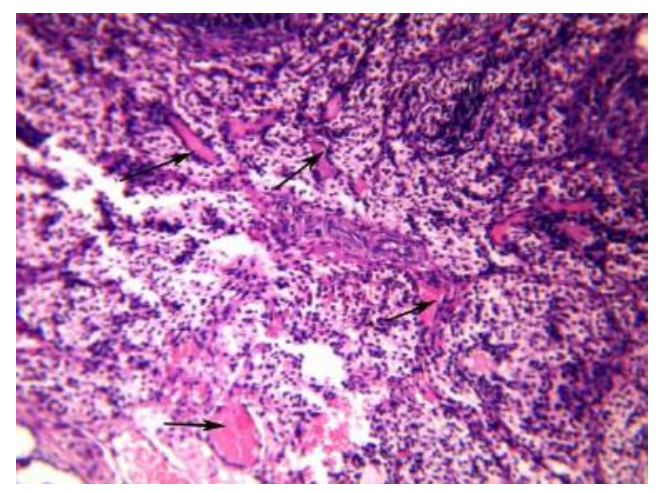

Fig.2. Photomicrograph of a section of ovary of group (2) showing congested dilated blood vessel (arrow) (H\&E) X: 200 47s.

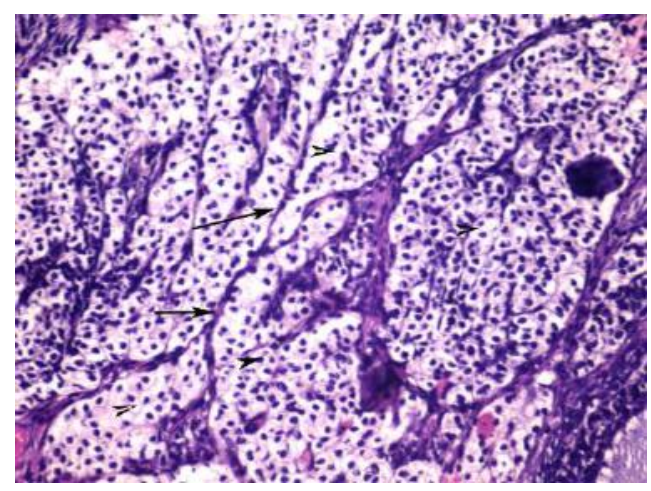

Fig.3. Photomicrograph of a section of ovary of group (2) showing fibrous stroma (arrow), degenerated follicles (arrow head) (H\&E) X400 $46 \mathrm{~s}$

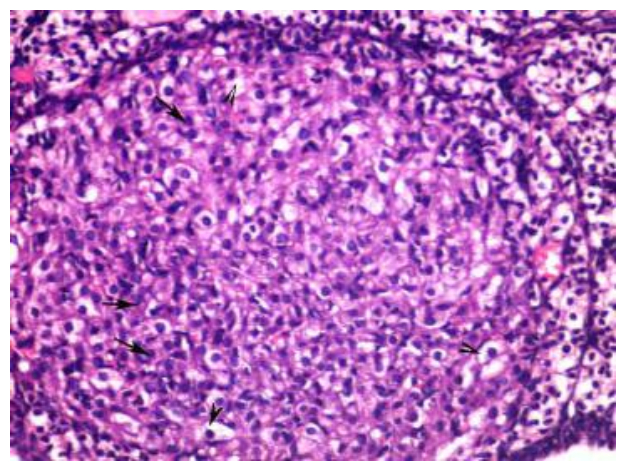

Fig.4. Photomicrograph of a section of ovary of group (3) showing intact granulosa lutein cells (arrow), vacuolated granulosa lutein cells (arrow head) (H\&E) X: $40069 \mathrm{~s}$ 
AbouZaid et al. (2018). BVMJ-35(1): 123-133

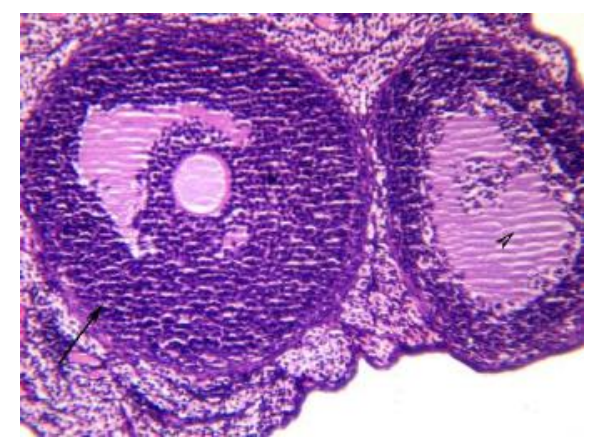

Fig.5. Photomicrograph of a section of ovary of group (3) showing normal graffian follicle (arrow), dilated antrum (arrow head) (H\&E) X: 40049 s.

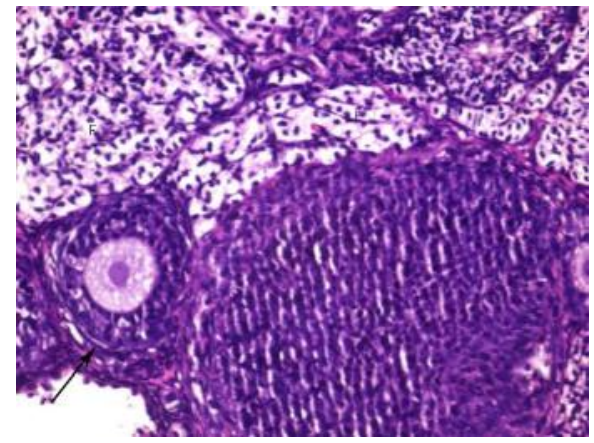

Fig.6. Photomicrograph of a section of ovary of group (3) showing normal tertiary follicle (arrow), atretic follicle (F) (H\&E) X: $40060 \mathrm{~s}$.

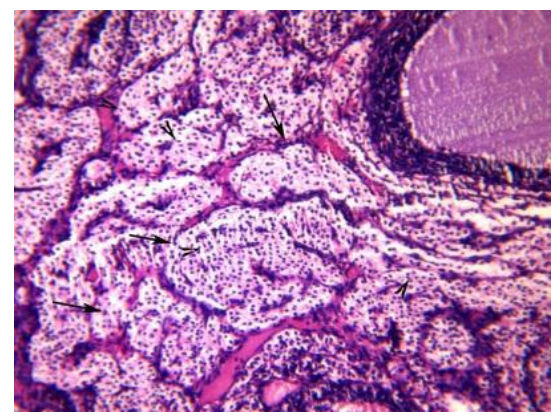

Fig.7. Photomicrograph of a section of ovary of group (4) showing atretic follicle (arrow), degenerated nucleus (arrow head) (H\&E) X: 200 48s

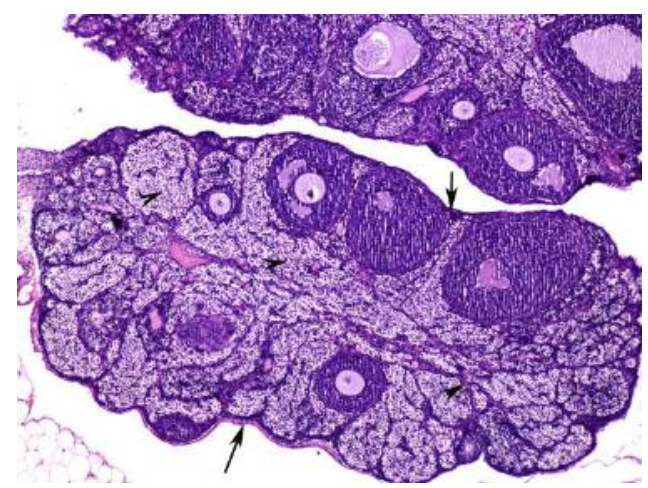

Fig.8. Photomicrograph of a section of ovary of group (5) showing thick capsule (arrow), atretic follicle (arrow head) (H\&E) X: 100 52s 


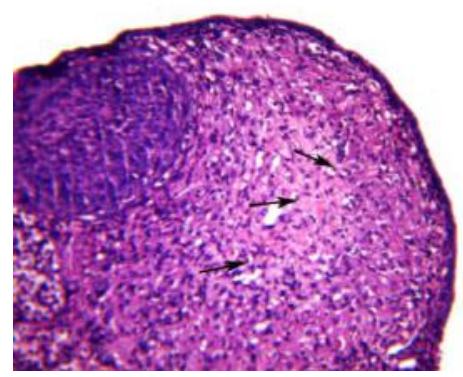

Fig.9. Photomicrograph of a section of ovary of group (6) showing fatty degenerative changes granulosa leutein cells (arrow) (H\&E) X : 40064 s.

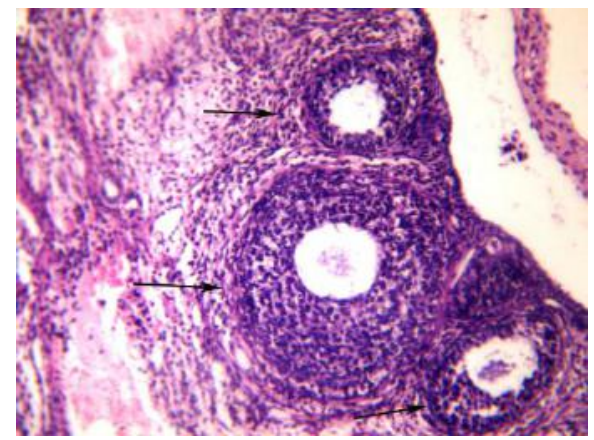

Fig.10. Photomicrograph of a section of ovary of group (6) showing cystic follicle (arrow) (H\&E) $\mathrm{X}: 20084 \mathrm{~s}$

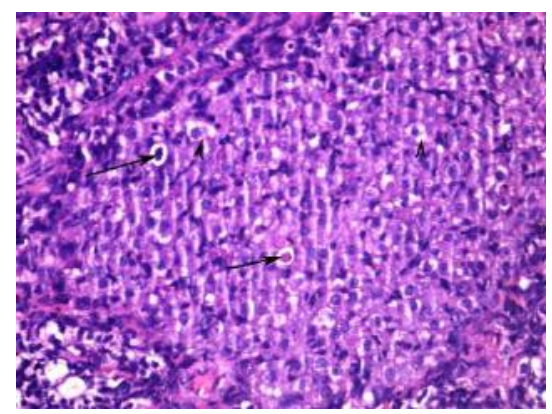

Fig.11. Photomicrograph of a section of ovary of group (7) showing hyaline body in granulose lutein cells (arrow), mild degenerative changes granulosa lutein cells (arrow head) (H\&E) X: 400 77s

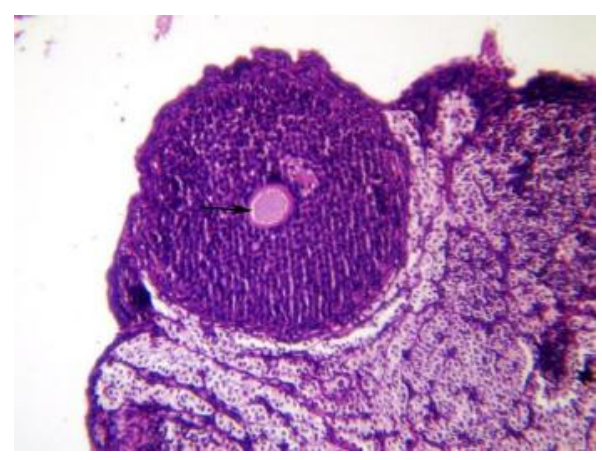

Fig.12. Photomicrograph of a section of ovary of group (7) showing regression of corpora luteum (arrow) (H\&E) X: 400 88s 


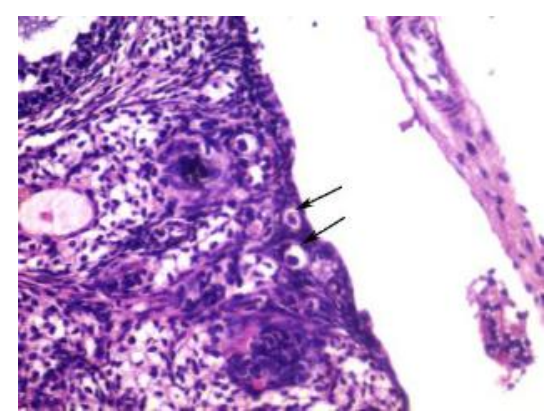

Fig.13. Photomicrograph of a section of ovary of group (7) showing normal primordial follicle (arrow) (H\&E) X: 400 82s

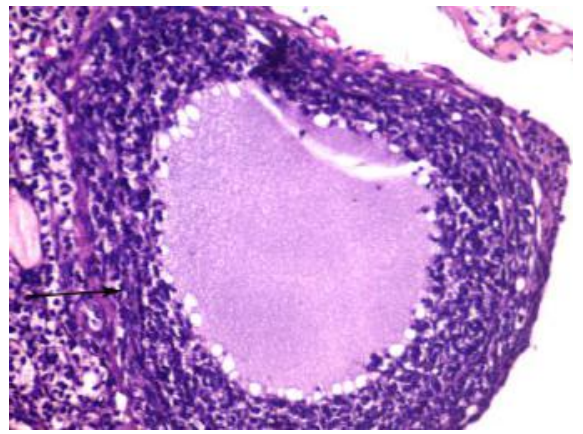

Fig.14. Photomicrograph of a section of ovary of group (7) showing cystic graffian follicle (arrow) (H\&E) X: 400 87s.

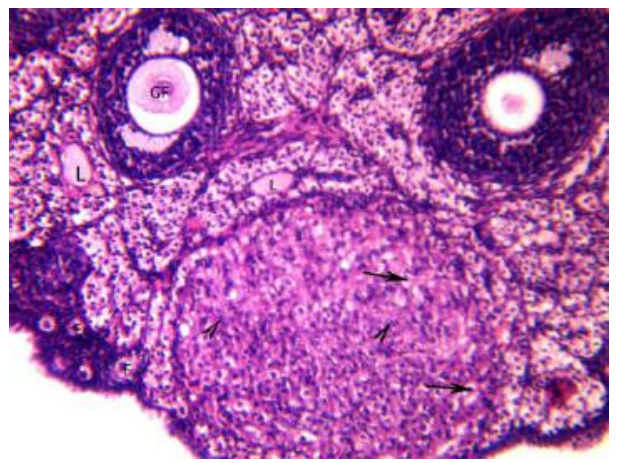

Fig.15. Photomicrograph of a section of ovary of group (7) showing dilated lymph (L), intact granulosa lutein cells (arrow head), vacuolated granulosa lutein cells (arrow), follicle (F), Graffian follicle

(GF)

$(\mathrm{H} \& \mathrm{E})$

$\mathrm{X}:$

400

$65 \mathrm{~s}$.

\section{DISCUSSION}

Women with PCOS are at increased risk of metabolic problems (impaired insulin resistance, impaired glucose tolerance, type two diabetes mellitus and cardiovascular disease), reproductive abnormalities (infertility, hyperandrogenism and hirsutism) and psychiatric illness (anxiety, depression and poorer quality of life). An ovulation is the predominant cause of infertility in PCOS.
The optimal treatment for infertile women with PCOS is not well established. Current guidelines suggest preconceptional counseling, lifestyle modifications including weight reduction and exercise, cessation of smoking, and a reduction in alcohol consumption. After these modifications, ovulation induction with anti-estrogen clomiphenes citrate, metformin or a combination of both may be trialed (Coker et al., 2016). 
The hormones including GnRH, LH/FSH ratio, estrogens, androgens, insulin, cortisol, $\mathrm{GH}$, vitamin D and PTH are found to be altered in PCOS patients. The decrease in the aromatase activity, increased LH/FSH ratio, rapid $\mathrm{LH} / \mathrm{GnRH}$ pulse, increased activity of $\mathrm{C}_{17,20}$-lyase, $17 \alpha$-hydroxylase, $5 \alpha$-reductase and $3 \beta$-HSD levels are some of the reasons for the increased androgen and decreased estrogen level seen in PCOS. Both adrenal and gonadal androgens contribute to hyperandrogenemia in PCOS. Other than through sex steroid receptors, androgens influence bone metabolism through various other pathways involving IL-6, prostaglandin $\mathrm{E}_{2}, \mathrm{PTH}$, vitamin $\mathrm{D}_{3}, \mathrm{TGF} \beta$ and IGF-1, IGF-2 and so forth.

Adrenal androgen excess in PCOS is associated with increased inactivation of cortisol which in turn leads to elevated level of TNF- $\alpha$ and IL- $1 \beta$ that could probably result in chronic inflammatory bone disease and bone loss (Abhaya and Sridhar, 2017). Approximately $20-30 \%$ of PCOS women demonstrate excess adrenal precursor androgen (APA) production, primarily using DHEAS as a marker of APA in general and more specifically DHEA, synthesis. The role of APA excess in determining or causing PCOS is unclear, although observations in patients with inherited APA excess (e.g., patients with 21-hydroxylase deficient congenital classic or non-classic adrenal hyperplasia) demonstrate that APA excess can result in a PCOS-like phenotype (Mark et al., 2015).

DHEA was chosen in this study for induction of PCOS by subcutaneous injection of daily doses of $(1 \mathrm{mg} / \mathrm{kg})$ for one month, and it was clear that PCOS hormonal imbalance appeared by the massive elevation of hormones (androgen, prolactin, TSH, AMH, LH/FSH ratio) concentrations and suppression of (estrogen and progesterone) concentrations which indicates that DHEA could be used for PCOS induction. In PCOS rates of abnormal range of androstenedione, LH/ FSH and LH in PCOs were significantly higher than those in the other anovulation, and abnormal LH/ FSH ratio is the main issue in the continuation of anovulatory state in PCOs subjects. Increased LH and decreased or normal FSH are due to (a) GnRH pulsatile secretion, i.e. at hypothalamic level. (b) high estrogen environment, i.e., at pituitary level. Clinically intense androgenization due to excess androgen production is observed in PCOs (Coker et al., 2016).

Hyperandrogenemia induces the increase in testosterone, androstenedione, dehydroepiandrosterone (DHEA), DHEA-S, 17-hydroxy progesterone and estrone (E1) (Dumitrescu et al., 2015). Leuproline acetate was given as LHRH analogue for suppression of the androgen activity and to bring back the hormonal imbalance to its normal state which appeared by the significant decrease of (androgen, prolactin, TSH, AMH, LH/FSH ratio) and increase in (estrogen and progesterone) if compared to DHEA only administrated group and it was the best achieving treatment to decrease the signs of PCOS.

This was the best improvement observed followed by cabergoline as a model of prolactin inhibitor, although the results was significant from control group but also it showed a significant improvement compared to DHEA only treated group. As prolactin secretion is controlled primarily by inhibition from the hypothalamus and it is not subject to negative feedback directly or indirectly by peripheral hormones. It exercises selfinhibition by a counter-current flow in the hypophyseal pituitary portal system which initiates secretion of hypothalamic dopamine, as well as causes inhibition of pulsatile 
secretion of gonadotropin releasing hormone (GnRH) (Coker et al., 2016).

This negatively modulates the secretion of pituitary hormones responsible for gonadal function like estrogen (Abha and Nisha, 2013). Phytoestrogen could play an important role in correcting the hormonal imbalance induced in PCOS. Many herbals used in remedies and folk medicines contain sufficient amount of phytoestrogens, with minimal side effects compared with other synthetic compounds, phytoestrogens could be a good choice in treating PCOS. Either one herb could be used or a combination of herbals, they have a characteristic effect in treating symptoms of estrogen deficiency or androgen elevation.

In this study three of them were chosen (soya, alfa alfa, and linseed) to evaluate their role in treating PCOS and their role were comparable, related to their phytoestrogen contents and they were significant from DHEA only treated group. The use of phytoestrogen is something common and advised by scientists. As by (Milo, 2000) who stated that Phytoestrogens, compounds derived from plants and converted into weak estrogenic substances in the gastrointestinal tract, are heavily promoted as the "natural alternative" to estrogen replacement therapy for postmenopausal women or women who have undergone a hysterectomy.

\section{Conclusion}

DHEA could be used for PCOS induction, Leuproline, cabergoline and phytoestrogen containing herbals could be used for treating PCOS symptoms.

\section{REFERENCES}

Abha, M. and Nisha, S; 2013: Mangal Hyperprolactinemia. J Hum Reprod Sci.; 6(3): 168-75.
Abhaya, K.; and Sridhar, M.; 2017: Hormonal alterations in PCOS and its influence on bone metabolism. Endocrinol, 232:99-113

Ankit, G.; Vivek, S.; Neelam, U.; Sandeep, G.; and Manvesh, S.; 2014: Flax and flaxseed oil: an ancient medicine \& modern functional food $\mathbf{J}$ Food Sci Technol. Sep; 51(9): 1633-53

Amirreza, R.; Ashwini, K.G.; Friederike, M.M.; Pegah, V.; 2017: Development of new gonadotropin-releasing hormone-modified dendrimer platforms with direct antiproliferative and gonadotropin releasing activityJ. Med. Chem. 60 (20) 8309-20.

Azam G.; Akram J.; Mohammad R.; Hasani G.; Mohammad E.G. 2015: Cabergoline plus metformin therapy effects on menstrual irregularity and androgen system in polycystic ovary syndrome women with hyperprolactinemia Iran J Reprod Med. Feb; 13(2): 93-100.

Azziz R.; Carmina E.; Dewailly D.; Diamanti E.; and Escobar, H. F.; 2009: The Androgen Excess and PCOS Society criteria for the polycystic ovary syndrome: the complete task force report. Fertil. Steril. 91, 456-88.

Belkiz, U.; Oya, N.S.; Ugur, O.; Teslima, D.; and Handan, S.; 2014: Histological investigation of the effect of soybean (Glycine max) extracts on the collagen layer and estrogen receptors in the skin of female rats Clinics (Sao Paulo).; 69(12): 854-861.

Coker, E.; Lahoud, R.; Abraham, S.; 2016: Polycystic Ovarian Syndrome and Eating Disorder Quality of Life: A Pilot Study. Reprod Med Genet Stem 
Cell Biol 4:171.

Crawford, E.; Moul, J.; Sartor, O.; and Shore, N.; 2015. Extended release, 6-month formulations of leuprolide acetate for the treatment of advanced prostate cancer: Achieving testosterone levels below $20 \mathrm{ng} / \mathrm{dl}$.Expert Opinion on Drug Metabolism \& Toxicology; 11(9)146574.

Dumitrescu, R.; Mehedintu, C.; Briceag, I.; Purcarea, VL.; and Hudita, D.; 2015: The Polycystic Ovary Syndrome: An update on metabolic and hormonal mechanisms. J Med Life. Apr-Jun; 8(2): 142-145.

Elizabeth, S.; Radmila, M.; Jonathan, F.; 2011: Dehydroepiandrosterone and memory. DHEA in Human Health and Aging, pp.399-413

Esmaiel, A.; Masome, K.F.; Leila S.; and Zohrab, A.; 2015: The effects of aqueous extract of alfalfa on blood glucose and lipids in alloxan-induced diabetic rats. Interv Med Appl Sci; 7(3): 124-128.

Fernando, L.V.; Armen, R.; Deukmed, j.; Shan, H.; Vitra S.; and Anthony D. M.; 2013Medically treated prolactinsecreting pituitary adenomas: when should we operate? BrJ Neurosurgery; 27(1) 56-62.

Heather, B. P.; and Wendy, J.; 2010: The pros and cons of phytoestrogens.Front Neuroendocrinol.; 31(4): 400-19.

Mark O.G.; Enrico, C.; and Ricardo, A.; 2015: DHEA, DHEAS and PCOS J Ster Biochem and Mol Biol; 145: 21325

Milo G.; 2000: Are phytoestrogens a "natural alternative" to estrogen replacement therapy? West J Med.; 173(4): 273.

Munir, I.; Yen, H. W.; Geller, D. H.; Torbati, D.; 2004: Insulin augmentation of 17alpha-hydroxylase activity is mediated by phosphatidyl inositol 3kinase but not extracellular signalregulated kinase $1 / 2$ in human ovarian theca cells. Endocrinology175-183

Russell, A.P.; Barbara, J.C.; and Carolyn, M.K.; 2016: Novel mechanisms for DHEA action.J Mol Endocrinol ; $56: 139-55$

Philippe, S.; Wenju, Z.; 2006: Phytoestrogen content of alfalfa cultivars grown in eastern Canada Science of food and agriculture; 86 (515):765-71.

Palla AH.; Khan NA.; Bashir, S.; Ur, R. N.; Iqbal, J; Gilani A.H.; 2015: Pharmacological basis for the medicinal use of Linum usitatissimum (Flaxseed) in infectious and noninfectious diarrhea.J Ethnopharmacol.; 160:61-8.

Renato, P.; 2018: Contemporary approaches to the management of polycystic ovary syndrome. Ther advnces endocrine and metbol; 9 (4) 123-34

Urbanek M.; 2007: The genetics of polycystic ovary syndrome. Natl Clin Pract Endocrinol Metab.; 3:103-111. 